\title{
Deformation Control Analysis of Unequal- Length Bridge Piles of Urban Rail Transit Tunnel Crossing Urban Expressway Elevated Bridge
}

\author{
Ye YUAN ${ }^{\mathrm{a}}$, Yang $\mathrm{WANG}^{\mathrm{b}, 1}$ and Mengda DING ${ }^{\mathrm{a}}$ \\ ${ }^{a}$ China Urban Construction Design \& Research Institute Corporation Limited, Beijing, \\ China \\ ${ }^{\mathrm{b}}$ Beijing Guodaotong Highway Design \& Research Institute Corporation Limited, \\ Beijing, China
}

\begin{abstract}
Taking the viaduct project of the main road bridge of Fushi road between Jinding Street station and Jinanqiao Station of line 11 of Beijing subway as the background, due to geological reasons, the length of the pile of the main road bridge of Fushi road is $60 \mathrm{~m}$ to the west of Xin'an road in the north, the pile length of the bridge east of North Xin 'an road is $21.5 \mathrm{~m}$, and line 11 of Beijing subway passes between two piles of unequal length. This paper simulates the whole construction process with the method of numerical analysis, analyzes the causes of the deformation of the bridge piles by calculation, puts forward the measures of grouting reinforcement in the whole section, sums up the deformation rules of the unequal length bridge piles, and puts forward the deformation control values, in order to ensure the safety of Rail Transit Construction, for the follow-up similar projects to provide a basis and reference.
\end{abstract}

Keywords. Urban rail transit, mining method, urban expressway, viaduct, unequal pile, deformation control

\section{Introduction}

In recent years, with the development and utilization of underground space, many cities in China have built urban rail transit. In the process of construction of Urban Rail Transit, it is often met with the situation of crossing the viaduct of urban expressway. The urban expressway is the main carrier of traffic flow, and the requirements of smoothness of road surface and Driving Comfort are higher, however, the deformation of the bridge piles will be caused by the stratum loss during the construction of the interval tunnel, which will directly affect the normal operation of the urban expressway.

\footnotetext{
${ }^{1}$ Yang Wang, Beijing Guodaotong Highway Design \& Research Institute Corporation Limited, Beijing, China; E-mail: 158762116@qq.com.
} 


\section{Deformation Control of Running Bridge under Urban Rail Transit}

The crossing project refers to the crossing of the new line and the existing line, under the condition of not affecting the safety of the existing line, the existing line is crossed above or under the ground according to the spatial relationship. The subway underpasses the operating bridge to belong to the crossing project category.

It is necessary to protect the existing bridge and ensure the safety of the operation of the new subway tunnel under the condition of safe construction. The protection measures for existing structures are studied in China.

Ma Wentian [1] used FLAC 3D to set up a model to compare and analyze the influence of "CRD construction method" and "PPA construction method" on adjacent bridge foundation piles in Hujialou Subdistrict station of Beijing subway, at the same time, the cast-in-place pile in the pilot tunnel plays the role of barrier reinforcement. He Xiaoli [2] adopted FLAC 3D software to simulate the influence of tunnel construction on the change of foundation pile and stratum of bridge, according to the adverse effects obtained from the simulation results, He Xiaoli designed the grouting reinforcement scheme of sleeve valve pipe on the ground surface, the monitoring results show that after grouting reinforcement, the deformation is controlled within the allowable range. Shishu [3] studied the influence of bored isolation pile and jet grouting isolation pile on existing high-speed railway viaduct. Zhang Guoxii [4] established an active protection management system for subway undercrossing existing bridges, in which risk identification and evaluation for subway undercrossing operating bridges is the premise of the whole active protection management system research, active protection comprehensive system is an important part of active protection management system, and construction dynamic monitoring is the information guarantee of active protection management system. The monitoring results show that the measured value is far less than the warning value, and the management system can realize the tunnel excavation under the premise of ensuring the safe operation of the existing bridge, which provides management and technical experience for similar crossing engineering.

In this paper, MIDAS GTS NX finite element software is used to simulate the construction process of the section tunnel mining method crossing the Fushi road viaduct with the background of Beijing Metro line 11 passing through the Fushi Road viaduct. This paper analyzes on the causes of the deformation of the bridge piles, advances some reasonable strengthening measures, and advances some safety control values, which provides a basis for the construction monitoring work, so as to ensure the safety of the viaduct of the interval tunnel and the Fushi road.

\section{Engineering Example}

\subsection{General Situation of Proposed Interval Tunnel}

The 24th Winter Olympic Games was held in Beijing in February 2022, and the official ski jumping event was held in the North district of Shougang Industrial Park.

Beijing Rail Transit Line 11 West Section (Winter Olympic branch line) Jinding Street $\sim$ Shougang Station, the length of the main line $3.44 \mathrm{~km}$, after the station access line and maintenance section length $0.96 \mathrm{~km}$, there are four stations, namely Jinding Street Station, Jinan Bridge Station, North Xin 'an road station, Shougang station. 
There are two transfer stations, one at Jinanqiao station, the other at line 6 and Line S1, the other at Shougang Station, and the other at the planned line R1.

The route passes through the model mouth area, Shimen road, North Xin 'an road to the West road of the planning repair shop. Through $\mathrm{K} 5+170 \sim \mathrm{K} 5+210$ of Fushi road pile, the step method with temporary invert is adopted in the section between Jinding street station and Jinan bridge station. About $17.7 \mathrm{~m}$ of earth cover. Distance between left and right lines is $11.8 \mathrm{~m}$. The clear distance between pile and viaduct is $4.2 \mathrm{~m}$ and $11.2 \mathrm{~m}$ respectively. The upper structure of Fushi Road viaduct is $40 \mathrm{~m}$ simply supported steel box girder, the Lower Structure Pier is column type, the foundation of 144 \# pier is six pile cap cast-in-place pile, the diameter of pile is $1.5 \mathrm{~m}$, the length of pile is $60 \mathrm{~m}$, the end bearing friction pile is $4.2 \mathrm{~m}$; The pile diameter is $1.8 \mathrm{~m}$, the length of the pile is $21.5 \mathrm{~m}$, and the net distance from the bridge pile to the left line is $11.2 \mathrm{~m} .3$ \# shaft is open cut, $25 \mathrm{~m}$ from Fushi road auxiliary road and $25 \mathrm{~m}$ in depth, as shown in figure 1 and figure 2 .

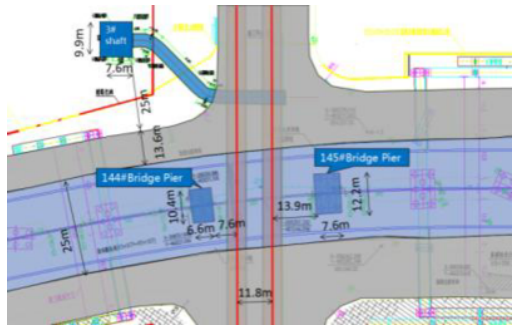

Figure 1. The relation between Jindingjie station and Jinanqiao station and the relative position of the road.

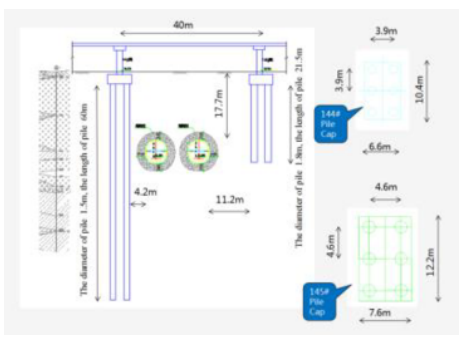

Figure 2. Schematic diagram of the relationship between the proposed utility tunnel and the road.

\subsection{Road Conditions}

The width of the Red Line of this section of the road is 40 metres and its cross-section is as follows: Main Road viaduct: Expressway 2 up and 2 down + bus lane, viaduct type. The central barrier shall be provided with a reinforced concrete guardrail with a width of $0.6 \mathrm{~m}$, a curb on both sides of the guardrail shall be $0.5 \mathrm{~m}$, a carriageway on both sides shall be $33.50 \mathrm{~m}$ and a curb on the outer side shall be $0.5 \mathrm{~m}$ wide, a reinforced concrete guardrail shall be provided on the shoulder of the road, with a width of $0.6 \mathrm{~m}$; The Cross section is 24.8 meters wide. The cover beam is cast with C50 concrete, and the superstructure at the crossing point is a $40 \mathrm{~m}$ simply supported steel box beam, as shown in figure 3 .

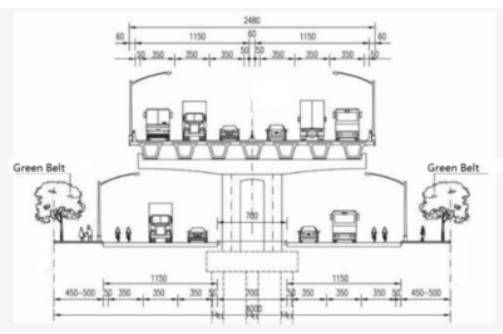

Figure 3. Road Section of Fushi Road. 
Substructure: The pier is connected by prestressed capping beam, the section size of pier column is $2(1.8 \mathrm{~m} 1.5 \mathrm{~m})$. The foundation is pile cap connected with bored pile, the diameter of 144 \# pile foundation is $\mathrm{d}=1.5 \mathrm{~m}$, and the diameter of 145 \# pile is 1.8 m. C40 concrete is used for pier, C30 concrete for pile cap and C25 concrete for pile, as shown in figure 4.

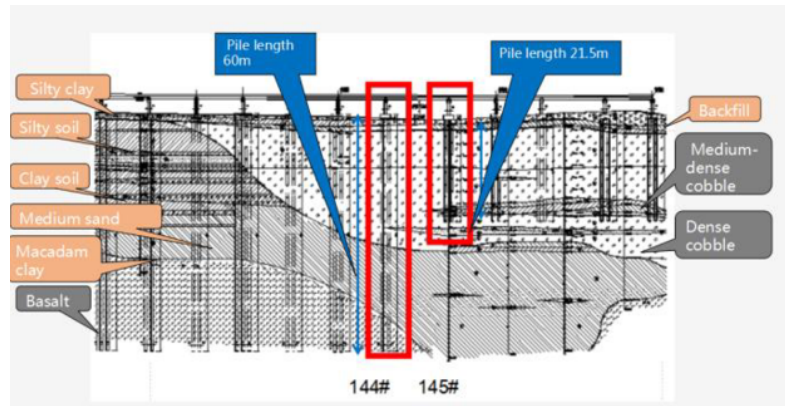

Figure 4. Section Diagram of relationship between foundation and stratum position of viaduct bridge of Fushi road main road.

The pile length to the east of 145 \# bridge pier is $21.5 \mathrm{~m}$, the geological conditions from top to bottom are mainly gravel fill and silt fill with medium-dense cobble layer, and the medium-dense cobble layer distributes below 4 meters on the ground surface. The pile length to the west of 144 \# bridge pier is $60 \mathrm{~m}$, from top to bottom, it is mainly silty clay, silt, clay, medium sand and crushed stone clay, until the depth of 40 meters below, basalt appears.

During the site investigation, there was phreatic water level higher than that of the interval tunnel. In addition, there was confined water with a head height of $9.7 \mathrm{~m}$ at the bottom of the tunnel.

\subsection{Analysis of the Influence of Interval Tunnel Construction on the Viaduct of the Main Road of Fushi Road}

\subsubsection{Model Building}

In this section, finite element method is used to analyze the influence of Jinding street station to Jinan Bridge Station, 3\#vertical shaft and horizontal passage construction on Fushi Road viaduct and Fushi Road Auxiliary road.

MIDAS GTS, a finite element software, is used to build a three-dimensional model of the substructure of the viaduct including the soil mass, the lower structure of the Fushi road viaduct, the $3 \#$ vertical shaft and the cross passage, this paper analyzes the influence of Jinding Street station-jinanqiao station interval, 3\# shaft and Cross passage construction on Fushi Road viaduct bridge and Fushi Road Auxiliary road. Mohrcoulomb constitutive model is used for soil, plate element is used for 3 \# shaft and cross passage, and elastic solid element is used for pier, pile cap and pile. The physical and mechanical parameters of soil used in the calculation are shown in table 1.

The dimensions of the model are $210 \mathrm{~m}, 170 \mathrm{~m}$ and $70 \mathrm{~m}$ along the $\mathrm{X}, \mathrm{Y}$ and $\mathrm{Z}$ directions, where $\mathrm{x}$ is the direction of the Fushi route, $\mathrm{y}$ is the direction of the undercutting of the interval tunnel and $\mathrm{Z}$ is the vertical direction. The lateral and underside of the model are the displacement boundary, the lateral displacement is 
limited in horizontal direction, the bottom displacement is limited in vertical direction, and the surface is a free surface. The model is shown in figures $5 \sim 8$.

Table 1. Physical and mechanical parameter table of Rock and soil mass.

\begin{tabular}{|c|c|c|c|c|c|}
\hline \multirow{4}{*}{$\begin{array}{l}\text { Floor } \\
\text { number }\end{array}$} & \multirow{4}{*}{$\begin{array}{l}\text { Soil layer } \\
\text { name }\end{array}$} & \multirow[b]{2}{*}{ Severe degree } & \multicolumn{3}{|c|}{ Direct Shear } \\
\hline & & & $\begin{array}{l}\text { Compression } \\
\text { modulus }\end{array}$ & $\begin{array}{l}\text { Cohesive } \\
\text { force }\end{array}$ & $\begin{array}{l}\text { Angle of } \\
\text { internal } \\
\text { friction }\end{array}$ \\
\hline & & $\gamma$ & Es1-2 & $\mathrm{C}$ & $\Phi$ \\
\hline & & $\mathrm{kN} / \mathrm{m}^{3}$ & $\mathrm{MPa}$ & $\mathrm{kPa}$ & $\circ$ \\
\hline (1) & $\begin{array}{l}\text { Miscellaneo } \\
\text { us fill }\end{array}$ & 17.5 & 4 & 0 & 8 \\
\hline (5) & cobble & 20.5 & 70 & 0 & 40 \\
\hline (7) & cobble & 20.8 & 100 & 0 & 45 \\
\hline
\end{tabular}

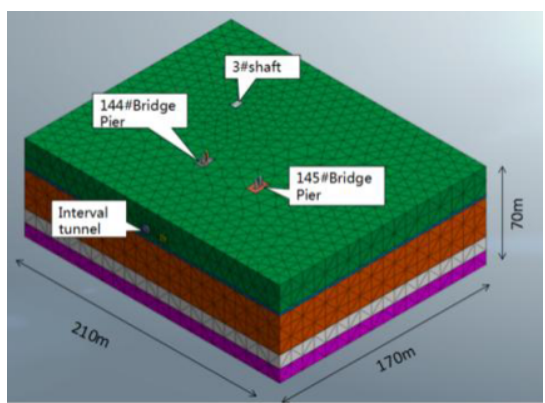

Figure 5. Model drawing of finite element calculation.

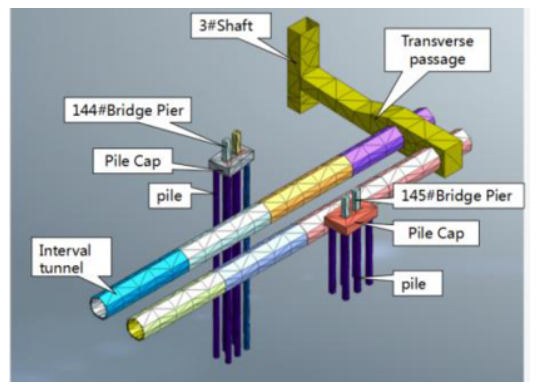

Figure 7. Detail drawing of the model of the underside structure of the bridge.

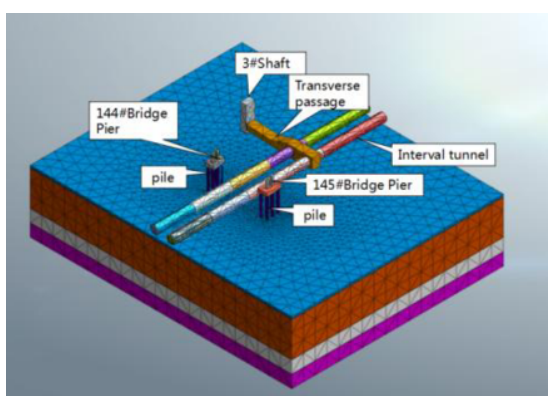

Figure 6. Detail drawing of finite element calculation model.

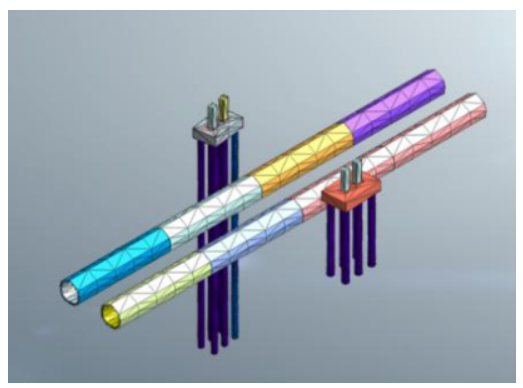

Figure 8. Model detail.

\subsubsection{Construction Process Simulation}

Working Condition 1: Shaft excavation and support; Working Condition 2: Excavation and structure of cross passage; Working Condition 3: Section left line first branch, excavation, lining completed; Working Condition 4: The first branch, excavation and lining of the section right line are completed. 


\subsubsection{Result Analysis}

Through numerical simulation, the vertical displacement of each bridge pier and the horizontal deformation of each pile are obtained, as shown in figures 9 12.

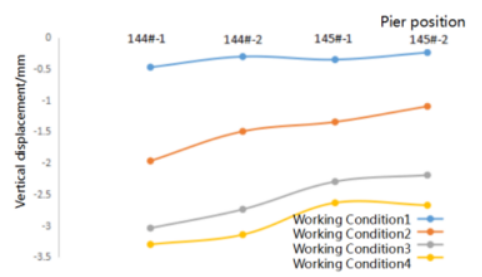

Figure 9. Vertical Displacement Diagram of unreinforced bridge section.

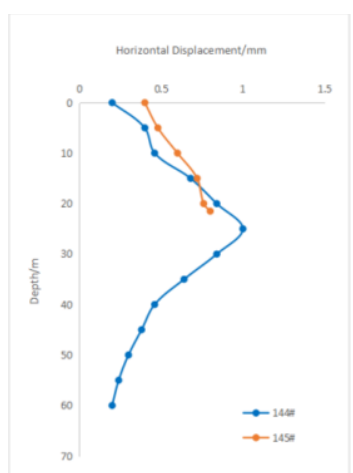

Figure 11. Horizontal displacement distribution of unreinforced bridge piles.

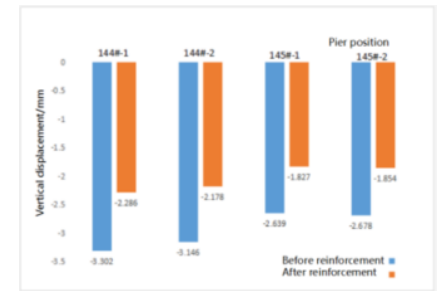

Figure 10. Comparison of vertical displacement of strengthened piers.

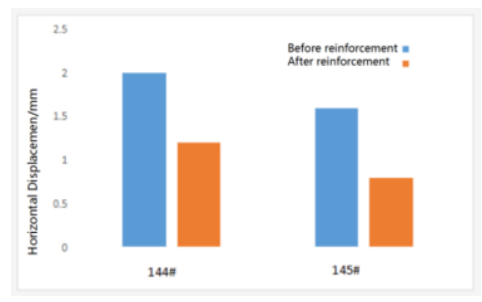

Figure 12. Comparison of maximum horizontal displacement of post-strengthened Bridge Piles.

The maximum settlement value of the road surface occurs at the Cross passage, the maximum settlement value of the auxiliary road surface of Fushi road is $7.74 \mathrm{~mm}$, and the maximum settlement value of the road surface after grouting reinforcement is $6 \mathrm{~mm}$.

In the process of excavation, the vertical displacement of Bridge Pier, the horizontal displacement of bridge pile and the settlement of road surface increase with the excavation of each section of tunnel. After full-section grouting reinforcement, the deformation value of pavement and bridge is reduced significantly, and the average deformation value is reduced by $30 \%$.

Because the depth of the long bearing layer of the bridge pile is different, the embedded depth of the 144 \# bridge pile is deeper than that of the 145 \# bridge pier, and the length and slenderness of the 144 \# bridge pile is larger than that of the 145 , so the horizontal deformation is larger.

\section{Road Deformation Control Requirements}

The Control Index of bridge deformation is mainly based on the ability of deformation to ensure the safety and normal function of bridge structure, and the degree of influence of Engineering on bridge structure. The construction control indicators are as follows: 
The settlement control value of each pier of Fushi Road viaduct is less than $3 \mathrm{~mm}$, the settlement control value of Longitudinal and longitudinal difference between piers is less than $2 \mathrm{~mm}$, the settlement control value of transverse difference between piers is less than $2 \mathrm{~mm}$, and the settlement control value of bidirectional inclination between piers is less than $1 \%$, the control value of the horizontal displacement of the pier and pile is less than $2 \mathrm{~mm}$, the control value of the settlement of the noise screen of the auxiliary facilities of the bridge is $5 \mathrm{~mm}$, and the control value of the inclined deformation of the noise screen is less than $3 \%$.

\section{Conclusion}

1) Although the length of the pile is not the same, the bearing layer is in the cobble layer, and the bearing capacity meets the requirement. The vertical displacement of the pile foundation is not affected by the crossing.

2) Because of the stratum loss, the long pile will cause the horizontal deformation of the pile, and the long pile will cause the horizontal displacement of the short pile.

3) Adopting full-section grouting reinforcement can effectively improve the vertical deformation of bridge pier and the horizontal deformation of bridge pile caused by interval tunnel construction.

4) It is suggested that the tracking compensation grouting should be adopted to strictly control the deformation of bridge piles. Combined with Internet technology, dynamic monitoring data is integrated and all data are collected and displayed at any time through software platform, which is more convenient to study data information and make protection adjustment in time.

5) The interval construction of mining method is a very complicated process, and it is more difficult to cross the piles of unequal length bridge. In this paper, the safety assessment of Interval Tunnel passing through unequal length bridge piles of urban expressway viaduct is only carried out in the aspect of bridge deformation, in order to minimize the impact of construction on viaduct.

\section{References}

[1] Ma WT. Study on the application of the method of tunneling pile in Hujialou Subdistrict station of Beijing subway. Shanxi Architecture. 2011 Aug; 37(13): 89-91.

[2] He XL. Influence of tunnel excavation in tong-hu section on deformation of existing bridge foundation piles. Xi'an: Xi'an University of Science and Technology; 2014 Jul; p.29.

[3] Shi Sh. Analysis of influence of isolation pile construction on deformation of adjacent viaduct piles. The Bridge of the World. 2012 Jul; 40(5): 54-58.

[4] Zhang GX. Research on the application of active protection management system for subway underpass bridge. Lanzhou: Lanzhou Jiaotong University; 2017 Dec; p. 27. 